\title{
Interactive comment on "Three-dimensional
} distribution of fine particulate matter concentrations and synchronous meteorological data measured by an unmanned aerial vehicle (UAV) in Yangtze River Delta, China” by Si-Jia Lu et al.

Anonymous Referee \#1

Received and published: 29 March 2016

The comment was uploaded in the form of a supplement:

http://www.atmos-meas-tech-discuss.net/amt-2016-57/amt-2016-57-RC1-

supplement.pdf 